\title{
Invent a safe Anti Needle stick Protector Device.
}

\author{
Mohammad Masoud Mahmoudi ${ }^{1}$, Asghar karbord ${ }^{2 *}$, Amirhossein Jafari Yeganeh ${ }^{3}$, Parastoo Ghadamabadi ${ }^{4}$, and Mahyar Mahmoudi ${ }^{5}$. \\ ${ }^{1}$ Nursing student, Young Researchers and elite club, Qazvin Branch, Islamic Azad University, Qazvin, Iran. \\ ${ }^{2}$ MSc Epidemiology of clinical research development unit, velayat hospital \& Faculty Members of Surgical Technologist Group of Paramedical \\ College, Qazvin University of Medical Science. Qazvin, Iran. \\ ${ }^{3}$ B.Sc. student, Facultry of Mechanical Engineering, K.N. Toosi University of Technology, Tehran, Iran. \\ ${ }^{4}$ B.Sc. Student, Mechanics, Electrical power \& Computer Faculty, Science \& Research Branch, Islamic Azad University, Tehran, Iran. \\ ${ }^{5}$ Department of Occupational Therapy, School of Rehabilitation, University of Social Welfare and Rehabilitation Sciences, Tehran, Iran. \\ *Corresponding Author: Asghar Karbord, MSc Epidemiology of clinical research development unit, velayat hospital \& Faculty Members of \\ Surgical Technologist Group of Paramedical College, Qazvin University of Medical Science. Qazvin, Iran.
}

Received date: March 17, 2021; Accepted date: March 26, 2021; Published date: April 01, 2021.

Citation: Mohammad Masoud Mahmoudi, Asghar karbord, Amirhossein Jafari Yeganeh, Parastoo Ghadamabadi, and Mahyar Mahmoudi. Invent a safe Anti Needle stick Protector Device, J. New Medical Innovations and Research, 2(3): DOI: 10.31579/jnmir.2021/012.

Copyright: () 2021 Asghar Karbord. This is an open-access article distributed under the terms of The Creative Commons Attribution License, which permits unrestricted use, distribution, and reproduction in any medium, provided the original author and source are credited.

\begin{abstract}
Background: Needle sticks and suffering from it, is one of the biggest problems for hospitals and medical staff. Needle stick can cause pathogen and sometimes disease transmission. The aim of this study is working on approaches for preventing needle stick.

Methods: This project started with a new researcher idea then by searching in the scientific content of articles and book, the title and proposal the project was compiled with opinion of the supervisor. Then model of the device was designed in collaboration with graphic \& mechanical engineers Fianccy. The main tool was invented by the researcher.

Results: Results of this study and other surveys can be one of the most effective ways to prevent needle stick. Also using safe protectors can decrease it significantly. Besides, modifying the preventive policies such as producing instruments like anti needle stick protectors is recommended.
\end{abstract}

Keywords: anti needle stick protector, needle sticks injury, ejections, medical system, health factors, safe needles, angiocatheter, syringe needle

\section{Introduction:}

Health from perspective of the world health organization (who): the science and the technique of preventing, presenting medical services for immediate diagnosis, treatment and growth in solving problems. Safety is one of the most important health factors in health and medical systems [1]. In health and medical system, the members of medical team are under physical and mental pressures that cause decreased therapeutic performance, moral harm and financial damage. Dipping the infected needle tip (NSIS), is one of the most current cause of physical, pathology and psychological risks for medical staff $[2,3,4,31]$. Needle stick: skin injuries caused by hypodermic syringes and other needle equipment that are contaminated by the patient's blood or other ejections ${ }^{1}$ [5], or injuries by sharps which are often due to breaking off a needle or other sharps contaminated by blood or other ejections [6,7]. Some of the most important reasons for needle stick are: working in the intensive care units (OR, RR, ICU...) [8], encountering stressors, compulsory working overtime morning shifts and using needle cap again $[9,10]$. These injuries are usually caused by carelessness and negliance in contact with sharps that can be generally prevented [13].Using safe needles can help preventing needle stick by 80 percent [14]. People who deal with sharps in medical center include: nurses $44 \%$, doctors $28 \%$, laboratory personnel
$15 \%$ and other services (cleaning and office staff, researchers and students) $13 \%$, who are exposed to needle stick [15]. Armstrong and his colleague in their research express that with improving hospital efficiency, safety culture for patients can be boosted [16]. According to a Japanese research in Saudi Arabia [17], Martins in Portugal [18], Nakhlahmadi in Iran [19], and Alamgir in Canada [20], nurses are exposed to needle stick more than others. From 35 million medical staff, about 2 million are exposed to pathogens through injury [21]. From this 2 million 740000 are exposed to Hepatitis B, 780000 are exposed to hepatitis $\mathrm{C}$ and about 170000 to HIV virus, which at this moment, more than $90 \%$ of these injuries happen in the developing countries [22, 23].Expanding diseases caused by needle stick is such as, risk of hepatitis transmission 37\%, 16B, hepatitis C 39\%, and Aids 4/4\% [24]. There are also other diseases like blast mycosis, Malta fever, Toxoplasmosis, Cryptococcus, Ebola, Syphilis, Malaria, and Rocky Mountain spotted fever [25]. Needle stick can cause an increase in direct and indirect costs for medical system [26]. According to researchers in united states, costs of treatment arising from needle stick for people without considering important diseases (HIV, HSV, HCV) are estimated about 2500 to 4000 dollars [27, 28]. Some approaches for preventing needle stick are changing the policy of hospitals, training, and using medical instruments. In other research, some prevention approaches are using safe needles, 
personal protection devices and training [30]. Now, considering the subject matter and results of researches, one of the ways of preventing needle stick is using protectors like anti needle protectors which are used for preventing needle stick and ejection from the exit needle place to safety box that is designed and manufactured. We'll talk about it' $\mathrm{s}$ structure in the following.

\section{Methods:}

This project started with a new researcher idea then by searching in the scientific content of articles and book, the title and proposal the project was compiled with opinion of the supervisor. Then model of the device was designed in collaboration with graphic \& mechanical engineers Fianccy. The main tool was invented by the researcher. This device is designed with solid work software by mechanical engineer and software developer and with science- theorical submission of the researcher (Mahmoudi) about making a device that can exit the infected needle and put it in the needle guard without exposing to the infected needle during the entire injection. The capacity is just for one needle presently (it will increase after it's made), so the person using this device puts the needle in the safety box that can be able to be used again. This idea was designed by solid work software and then the file of that was transferred to the lab by researcher and mechanical engineer for hardware designing and replica. Anti-needle stick replica was checked in terms of morphology all aspects, shape, and size, according to the needle syringe and standard needle angio catheter (shape 1), and it was designed again by a software developer, after changing shape and size (shape 2). After designing, the file was given to 3D printer model (season 4 desktop) and then the device intended were made. The material was plexiglass (transparent polycarbonate). It will address the components and performance of the protector in the following: Anti needle stick protector is made of three cubes, (first cube: length: $30 \mathrm{~mm}$, width: $14 \mathrm{~mm}$, height: $12 \mathrm{~mm}$, the second cube: length: $30 \mathrm{~mm}$, width: $16 \mathrm{~mm}$, height: $14 \mathrm{~mm}$, third cube: length: $30 \mathrm{~mm}$, width: $18 \mathrm{~mm}$, height: $16 \mathrm{~mm}$ ), a regulator twist (shape 1 , number
1), a rotary plate ${ }^{7}$ (shape 2 , number 6 ), and heparin- lock cap (shape 1 , number 8 ). At first, 3 cubes (shape 1, number 3, 4, 5) are placed into each other (like the following mugs) and rotary plate (shape 2, number 6), sets up on the angio catheter needle. After adjusting and fastening, the nurse takes out the needle of angio catheter, and then cube number 2 (shape1, number 4) and cube 3 (shape 1, number 5), move forward by the nurse's other hand. So, the needle locates into the protector. Heparin- lock cap (shape 1 , number 8 ) that is placed on the third cube (shape 1, number 5), moves down after third cube is completely open and then covers the front part. After taking out the angiocatheter and opening the third cube by the nurse, (shape 1, number 5) and then moving down the heparin- lock (shape 1, number 8 ) he/she prevents bleeding by putting heparin cap on the angiocatheter. Heparin-lock site (shape 1, number 9) is on the heparinlock cap (shape 1, number 8), and the heparin- lock is installed before the heparin- lock cap is moved down. The other function of needle angiocatheter protector rail chamber with heparin- lock is preventing needle stick by syringe. After connecting the needle to the syringe, the nurse puts the needle tip, that is covered by needle cap, on the rotary plate (shape 2, number 6). After fastening the needle cap with rotary plate (shape 2, number 6), the nurse moves the first cube (shape 1, number 3 ) and second cube (shape 1, number 4) toward syringe with his hand, that causes covering the length syringe and placing it into the case (protector). The nurse does the injection with taking out the needle from the cap and then without touching the needle, returns it to the cap that is inside the case (protector). And after completely placing the needle into the cap by rotating the body of the syringe, needle with it's cap disparts from syringe and remains into the case(protector) (the nurse' $s$ hand is on the outer surface of the case (protector), when needle is rotating). With transferring the case to the top of safety box and opening the regulator twist (shape 1, number 1), the cap containing the needle, releases from the rotating board (shape 2, number 6), and transfers to the safety box and thus the nurse's hand definitely won't touch the needle and it's cap

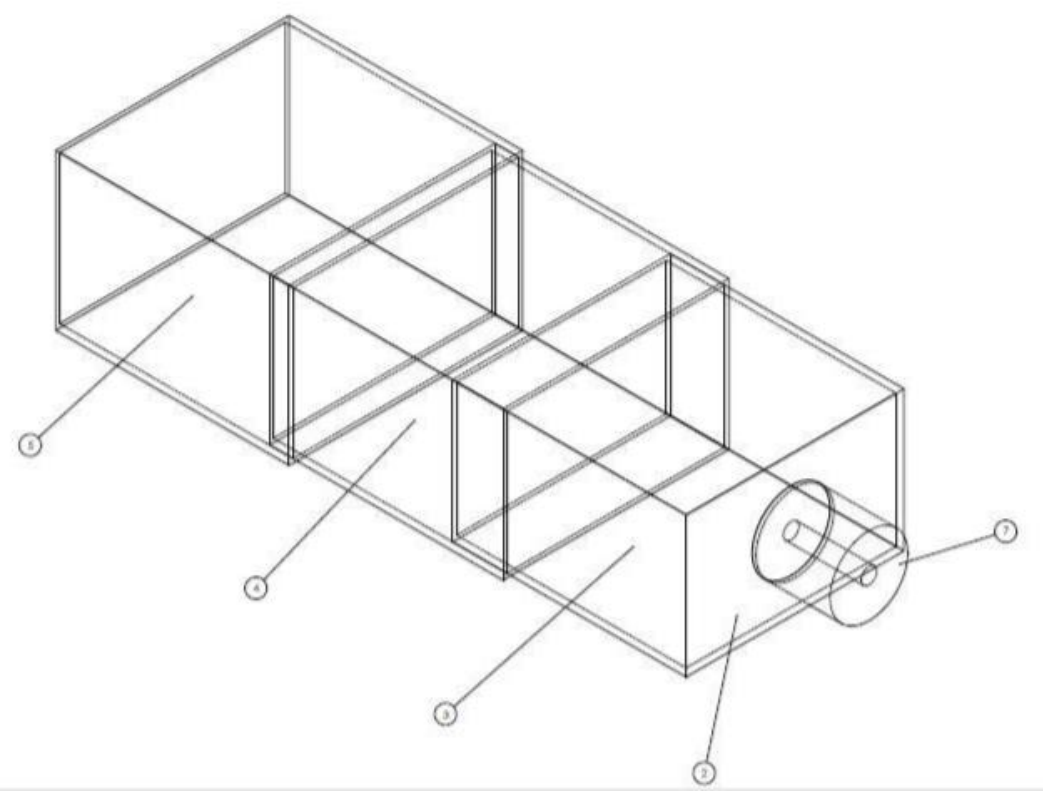




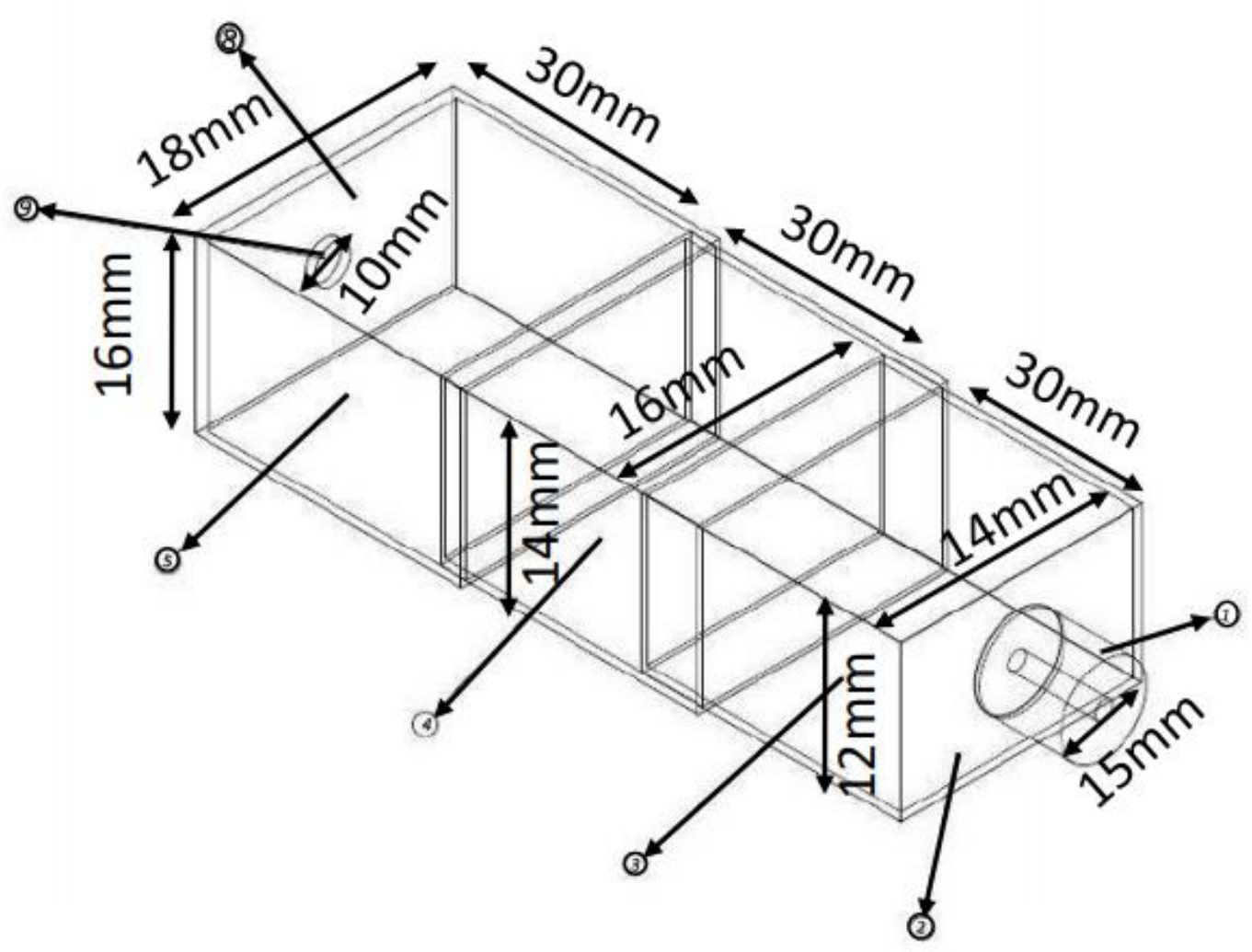

Figure 2: Anti-needle stick replica Measurements.

According to Figure 2:

1-Regulator twist

2- Common page

3-first cube

4-second cube

5-Third cube

8- Heparin-lock cap

9-Heparin-lock site

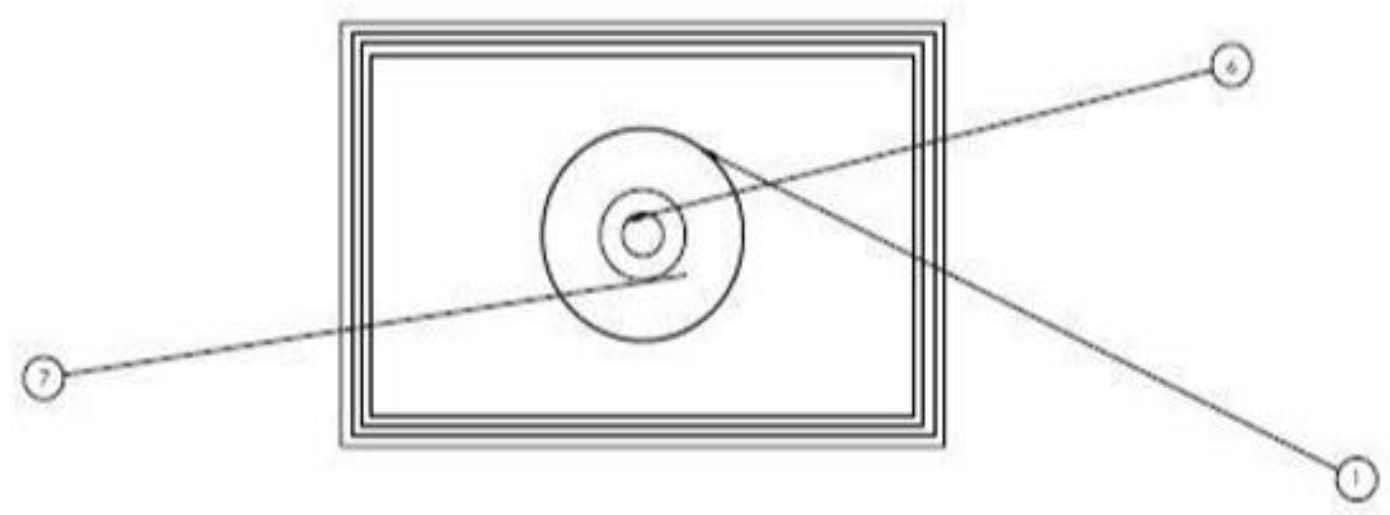


2-rotary plate

3-Rotary plate axle

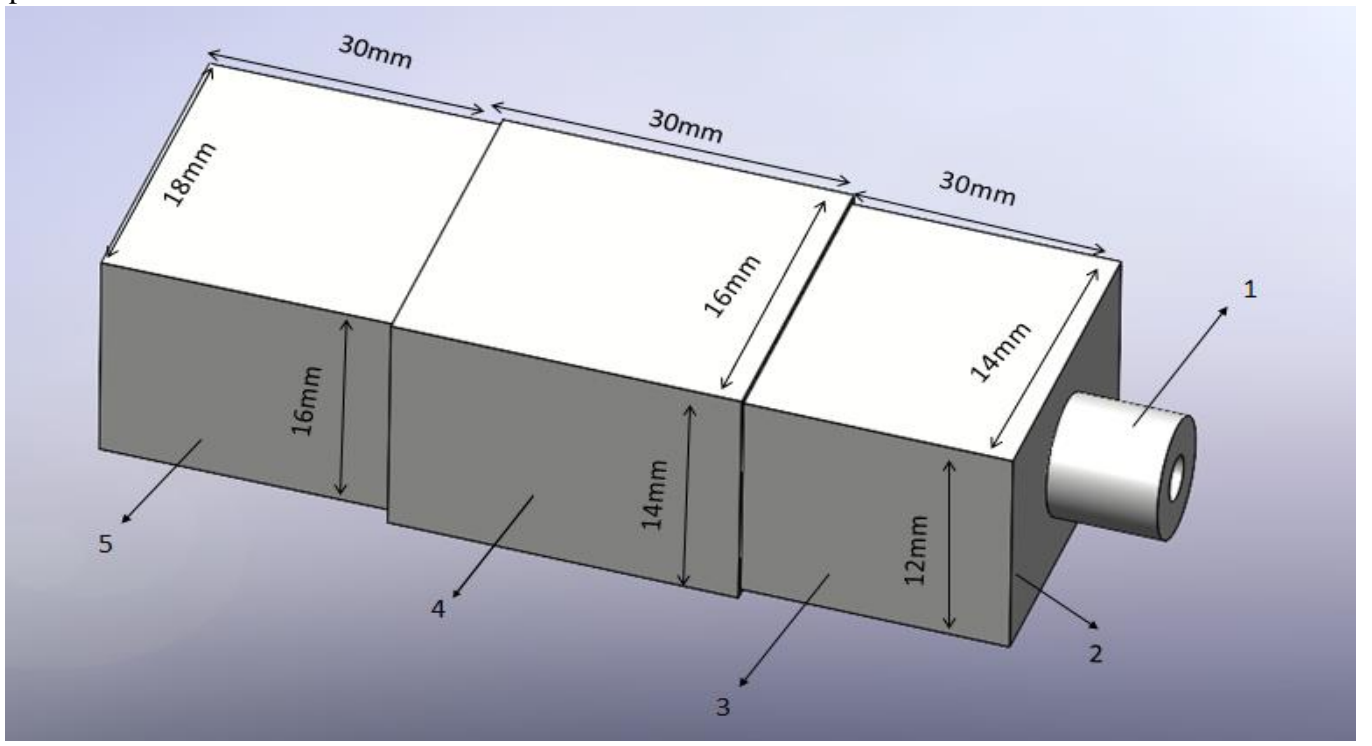

Figure 4:

According to Figure 4:

1-Regulator twist

2- Common page

3-first cube

4-second cube

5-Third cube

\section{Discussion}

This research has been done in the field of medicine and medical engineering. Due to the extent of the needle spread of medical staff when providing medical care to the drug, the use of preventive equipment is felt to prevent this problem. The purpose of designing this anti-needle stick is to reduce the needle rate of caregivers. Due to the innovative design of this design, it can be used for both needle angiocatheter and syringe needle. Advantages of this design include use for both angiocatheter and syringe, small size and portability, sterility, complete disposal of the needle without touching the hand, low cost and economic due to the financial losses caused by the needle stick. Also, according to the research of Livia et al. (2018), a study entitled Needle stick with safety devices and its prevention with an integrated structure [32], and this research, the use of preventive equipment to prevent needle stick is suggested.

\section{Result}

Results of this study and other surveys can be one of the most effective ways to prevent needle stick. Also using safe protectors can decrease it significantly. Besides, modifying the preventive policies such as producing instruments like anti needle stick protectors is recommended. We are ready to cooperate with all institutions and individuals in the fields of economics, education, research and health for this idea. If you wish, please contact us via masoudmahmoudi515@ymail.com email.

\section{Conclusion:}

This device is protective for group therapy that reduces nieedle stick by up to $98 \%$ during Interamuscular, intravenuos and subcutaneous injection. As a result, it causes significant reduction of diseases that can be transmitted by this methode such as hepatitis B\& C and AIDS, etc.

This tool can be produced in different sizes and Shapes for all of type injection and apolications in operating room ,hospital wards ,emergrncy and out patient injection rooms.

The researcher also has the scientefic ability to produce this medical device In digital format.

\section{References:}

1. Marin HF (2004). Improving PatientSafety with Technology. IntJ Med Inform; 73(7-8): 543-546.

2. VoseJ, Mcadara J (2009). Reducing scalpel injuries in the operating room. AORN J; 90(6): 867-872.

3. Doebbeling BN, Vaughn TE, McCoy KD, Beekmann SE, Woolson RF, Ferguson KJ, Torner JC (2003). Percutaneous injury, blood exposure, and adherence to standard precautions: are hospital-based health care providers still at risk? Clinical Infectious Diseases. 37(8):1006-1013.

4. Whitby RM, McLaws ML (2002). Hollow-bore needlestick injuries in a tertiary teaching hospital:epidemiology, education and engineering. Medical Journal of Australia..177(8):418-422.

5. .Rele M, Mathur M, Turbadkar D (2002). Risk of needle stick injuries in health care workers- A report. Indian J Med Microbiol. Oct- Des; 20 (4): 206- 207. 
6. Adib-Hajbaghery M, Lotfi MS (2013). [Behavior of healthcare workers after injuries from sharp instruments]. Trauma Monthly; 18 (2): 75-80. Persian.

7. Nouhi E, Khoshnoud Z, Seyed Adel M (2010). [Needle stick and sharp object injuries among nursing \& midwifery students of Kerman University of Medical science, 2007]. IJNR.; 5 (18):1823. Persian.

8. Cho E, Lee H, Choi M, Park SH, Yoo IY, Aiken LH (2013). Factors associated with needlestick and sharp injuries among hospital nurses: A cross-sectional questionnaire survey. Int J Nurs Stud; 50(8):1025-1032.

9. Gershon RR, Pearson JM, Sherman MF, Samar SM, Canton AN, Stone PW (2009). The prevalence and risk factors for percutaneous injuries in registered nurses in the home health care sector. Am J Infect Control.;37(7):525-533.

10. Khalouei A, Iranpour A, Hamzehnezhadi S, Rahmanian Ke (2010). [Study On Epidemiology Of Needle Stick Injury Among Nursing Personnel Of Kerman University Hospitals. Kerman, Iran In (2006-2007)]. Jahrom Medical Journal; 7 (3): 42-49. Persian.

11. Moro PL, Moore A, Balcacer P, Montero A, Diaz D, Gómez V, et al (2007). Epidemiology of needlesticks and other sharps injuries and injection safety practices in the Dominican Republic. Am J Infect Control. 35(8):552-559.

12. Beyera GK, Beyen TK (2014). Epidemiology of exposure to HIV/AIDS risky conditions in healthcare settings: the case of health facilities in Gondar City, North West Ethiopia. BMC Public Health;14(1):1-8

13. Azap A, Ergönül Ö, Memikoğlu KO, Yeşilkaya A, Altunsoy A, Bozkurt G-Y, et al (2005). Occupational exposure to blood and body fluids among health care workers in Ankara, Turkey. Am J Infect Control; 33(1):48-52.

14. Fisman DN, Harris AD, Sorock GS, Mittleman MA (2003). Sharps-Related Injuries in Health Care Workers: A CaseCrossover Study. Am J Med;114(8):688-694.

15. Needlestick injuries. 2003 (citedJanuary23,2008). Available from: http://www.jr2.ox.ac.uk/bandolier/Extraforbando/ needle.pdf.

16. Armstrong KJ, Laschinger H (2006). Structural empowerment, magnet hospital characteristics, and patient safety culture: making the link. Journal of Nursing Care Quality; 21(2): 124-132.

17. B. Braun, Sharps Injury, Risk Prevention in Infusion Therapy - W. 01.06.11/1 Nr. 6069095 Edition: 06/2011.

18. . Buraidah A-Q (2005). Epidemiology of needlestick injuries among health care workers in a secondary care hospital in Saudi Arabia. Ann Saudi Med.;25(3):233-238.

19. Martins A, Coelho AC, Vieira M, Matos M, Pinto ML (2012). Age and years in practice as factors associated with needlestick and sharps injuries among health care workers in a Portuguese hospital. Accid Anal Prev;47:11-15.

20. Nakhle Ahmadi H, Khazaei T (2007). [Assessing the performance and knowledge of the medical staff of Imam Reza \& Vali-asr hospitals in Birjand on the injuries resulting from needle stick]. Modern Care Journal;4(1):41-46. Persian.

21. Alamgir H, Cvitkovich Y, Astrakianakis G, Yu S, Yassi A (2008). Needlestick and other potential blood and body fluid exposures among health care workers in British Columbia, Canada. Am J Infect Control. 36(1):12-21.

22. . http://www.ncbi.nlm.nih.gov/pubmed/23020050.

23. WHO Needle stick injuries; Implementation of pilot projects to reduce sharps injuries in health care workers; World Health Organization 2005; (www.who.int/occupational.health/topics/ needleinjuries/en/print.html).

24. Laishram J, Keisam A, Phesao E, Tarao MS, Laloo V, Devi HS (2013). Prevalence of needle sticks injuries among nurses in a tertiary care hospital and their immediate response. International Journal of Medicine and Public Health; 3 (4): 257-260.

25. Bell DM (1997). Occupational risk of human immunodeficiency virus infection in healthcare workers: an overview. Am J Med; 102(suppl 5B):9-15.

26. http://www.cdc.gov/niosh/stopsticks/sharpsinjuries.html

27. Hatcher, J.B (2002). Reducing Sharps Injuries Among Health Care Workers - a sharps container quality improvement project, in: Journal on Quality Improvement, Vol. 28, No 7.

28. Tan et al (2001). Preventing Needlestick Injuries in Health Care Settings; Arch. Intern Med. 161: 334-340.

29. Akpinar-Elci M, Bidaisee S, Durgampudi P, Radix R, RodriquezGuzman J, Nguyen MT, et al (2018). Needlestick injury prevention training among health care workers in the Caribbean. Rev Panam Salud Publica;42:93.

30. Santos LT, Rocha FLR, Marziale MHP (2018). Needlesticks with safety devices and accident prevention: an integrative review. Rev Bras Enferm [Internet]. 71(6):3084-3092. DOI: http://dx.doi.org/10.1590/0034-7167-2017-0719.

31. AlDakhil, L., Yenugadhati, N., Al-Seraihi, O. et al (2019). Prevalence and associated factors for needlestick and sharp injuries (NSIs) among dental assistants in Jeddah, Saudi Arabia. Environ Health Prev Med 24, 60. doi:10.1186/s12199019-0815-7.

32. Santos LT, Rocha FLR, Marziale MHP (2018). Needlesticks with safety devices and accident prevention: an integrative review. Rev Bras Enferm [Internet]; 71(6):3084-92. DOI: http://dx.doi.org/10.1590/0034-7167-2017-0719 